\title{
ASSESSING THE MARKET, FINANCIAL AND ECONOMIC RISK SOURCES BY CZECH AND SLOVAK SMES
}

\author{
Ján Dvorský \\ Tomas Bata University in Zlín, Faculty of Management and Economics, Department of Business Administration \\ Zlín, Czech Republic \\ j1dvorsky@utb.cz \\ Zora Petráková \\ Faculty of Civil Engineering, Slovak University of Technology, Institute for Forensic Engineering, Slovak \\ Republic \\ zora.petrakova@stuba.sk
}

\section{Jiří Polách}

Institute of Entrepreneurship and Marketing, University of Entrepreneurship and Law, Czech Republic jiri.polach@,vspp.cz

\begin{abstract}
The market, economic and financial risks are the most important risks, which determine the quality and performance of small and medium sizes enterprises. The main objective of the article is to evaluate the most important sources of market, economic and financial risk between Slovak and Czech SMEs according gender and size of enterprise. The questionnaires of 895 entrepreneurs were collected and prepare on evaluating in the year 2018. The statistical hypotheses were accepted through the mathematical method as is Z-score. The gender of entrepreneur and size of enterprises between Slovak and Czech entrepreneurs is a significant factor of evaluating the sources of economic risk, as is development of the tax and insurance burden; weak availability of the financial resources (loans, foundations); development of the interest rates; growing prices of all types of energy. According to the evaluation of entrepreneurs, the intensity of sources of economic risk in Slovak business environment is higher than in Czech business environment.
\end{abstract}

KEYWORDS: economic risk, financial risk, gender, market risk, risk source, small and medium-sized enterprise

JEL CLASSIFICATION: M21, G32, L52, L36

Received: November 28 $8^{\text {th }}, 2019$

1st Revision: December $7^{\text {th }}, 2019$

Accepted: December $17^{\text {th }}$, 2019

DOI: 10.2478/IJEK-2019-0008

Reference: Dvorský, J., Petráková, Z., Polách, J. (2019). Assessing the Market, Financial, and Economic Risk Sources by Czech and Slovak SMEs. International Journal of Entrepreneurial Knowledge, 7(2), 30-40. doi:10.12345-0008

\section{INTRODUCTION}

A set of influences affecting the existence and development of all business activities is generally denoted as business environment. The results of business activities are considerably dependent on the business environment a company operates in (Buganová \& Moricová, 2017; Fabuš, 2017). Conditions under which companies operate, or develop their activities, have a significant impact on their performance, competitiveness and growth potential, as well as they determine the attractiveness of a particular state for foreign investors (Fabuš, 2017).

Small and medium enterprises are facing constant changes in the business environment and the way to deal with these changes also depends on the ability of the enterprise to adapt and accept the variability 
of everyday life (Petrenko et al., 2017; Karpak \& Topcu, 2011). The issues of important risks management in small and medium-sized enterprises (SMEs) have been analysed and discussed for a long time (Havierniková \& Kordoš, 2019; Bilan et al., 2017).

The paper is structured as follows. Section 2 briefly introduces the risk management process, the importance of entrepreneurs of companies. Section 3 introduces literature review of the key risks and their sources in business environment. Section 4 describes the empirical background, i.e. aim of the article, the methodology of data collection, formulate statistical hypotheses and methods. Section 5 presents and the main and important empirical results. Section 6 compares the findings of the paper with the findings of other authors. In the concussion, the limits of research and the future research of authors are presented.

\section{SHORT THEORETICAL BACKGROUND}

The market risk is the exposure to a potential loss that would be triggered by changes in market prices or rates. All companies are exposed to some forms of the market risk. The level and form of the market risk exposure differ by industries, and by companies within an industry. The major types of market risks are (Lam, 2003): interest rate risk, foreign exchange risk, commodity risk, equity risk, basis risk, other market driven risk. In addition to the most common market risk types listed above, there are other market risks, such as option risks and exposures to other market prices (Hudakova et al., 2017).

An SME's approach to risk management is also dependent on its attitude to sustainable development, as can be seen in the Czech Republic (Dobeš et al., 2019) and in Slovenia (Mikušova, 2017). In both countries a company's risk management policy is very dependent on its managers' responsibility, both to owners and to other stakeholders.

If the companies do not identify financial and economic risks and do not apply a risk management strategy, their sustainability can be affected (Belas \& Sopkova, 2016). The most serious risks are economic (Kozak \& Danchuk, 2016) and financial risks (Oláh et al., 2019; Leon, 2015). According to Pochitaev \& Filippova (2016), there are several types of financial risk, including loan risk, asset-backed risk, credit risk, foreign investment risk, liquidity risk, market risk, and operational risk, etc. Tinoco \& Wilson (2013) state that financial risk can cause SMEs to default due to a lack of bank financing.

Additionally, according to Jegadeeshwaran and Basuvaraj (2019), SMEs are not the attractive client for bank lenders. Degryse and van Cayseele (2000) examined the relationship between interest rates and loan amount. Koisova et al. (2017) studied relations between SMEs credit availability and banks' organisational structure. They stated that companies size and age have an important role in obtaining external finance (Virglerova, 2018).

Additionally, Kljucnikov et al. (2017) asserted, that smaller and younger companies have bigger problems with external financing and also pay higher prices. Further Meyer and Meyer (2017) explained that conditions for SMEs have worsened because of the global financial crisis. Studies, available in the Slovak Republic, do not analyse the evolution, do not identify barriers and do not formulate proposals, that may be useful for SMEs external financing (Hudakova et al., 2018).

\section{AIM, METHODOLOGY AND METHODS}

The main objective of the article is to evaluate the most important sources of market, economic and financial risk between Slovak and Czech SMEs according gender and size of enterprise. The statistical unit of research was a single enterprise (manager). The entrepreneurs were selected with using "the random selection method" (with using function "Randbetween") from specialized database of 
entrepreneurs for each country (Slovakia - Cribis database, Czech Republic - Albertina database. Out of 895 small and medium-sized enterprises analysed Slovakia represented 54.4\% respondents and the Czech Republic 45.6\% respondents.

Entrepreneurs could give their opinion to the risk sources which affect the company intensively - a very low intensity (V1); a low intensity (V2); a medium intensity (V3); a high intensity (V4) and a very high intensity of the risk source (V5). The sources of the selected risks are for:

- The market risks (R1): involve loosing the customers (R11); strong competition in the line of business (R12); stagnation of the market (R13); unreliability of the suppliers (R14);

- The economic risks (R2): development of the tax and insurance burden (R21); weak availability of the financial resources (loans, foundations) (R22); development of the interest rates (R23); growing prices of all types of energy (R24);

- The financial risks (R3): insufficient company profit (R31); indebtedness of the company (high share of the foreign capital) (R32); unpaid receivables (R33); inability to pay obligations (insolvency) (R34).

The author considers important to investigate the differences in the values of the market, economic and financial risk sources - the answers bring a high intensity of the risk source (V4) and a very high intensity of the risk source (V5). To fulfill the main task of the paper the authors formulated the following statistical hypotheses:

H1: The gender is the statistical significant factor of evaluating the sources of market risk (H1A), the financial risk (H1B) and the economic risk (H1C) between Slovak and Czech enterprises.

$\mathrm{H} 2$ : The size of enterprise is the statistical significant factor of evaluating the sources of market risk $(\mathrm{H} 2 \mathrm{~A})$, the financial risk $(\mathrm{H} 2 \mathrm{~B})$ and the economic risk $(\mathrm{H} 2 \mathrm{C})$ between Slovak and Czech enterprises.

In order to evaluate the given hypotheses essential to meet the main goal of the article, the author used the descriptive statistics tools (pivot table, relative and absolute frequency) in the first step. In order to determine the frequency of entrepreneurs' answers, we used a simple sorting of the statistical sign (R11, ..., R34) and the sorting according to two statistical sign (selected country and type of answer (V1, V2, ..., V5)). Descriptive characteristics are needed to calculate Z-score. The Z-score method was applied to accept or reject statistical hypotheses $(\mathrm{H} 1 \mathrm{~A}, \ldots, \mathrm{H} 2 \mathrm{C})$. The assumption for carrying out the Z-test (normal distribution of samples according to statistical features and the representativeness of the sample - number of entrepreneurs) were fulfilled. All these results were performed using the SPSS Statistics analytical software for data evaluation.

The structure of the entrepreneurs' characteristics who filled in the questionnaire was as follows: Slovakia (SR): male (M) entrepreneurs - $66.8 \%$; female $(\mathrm{F})$ entrepreneurs - $33.2 \%$; the age - up to 30 years $-20.3 \%$; from 31 to 50 years $-55.2 \%$; over 50 years $-24.5 \%$; the achieved education - secondary school without the school-leaving exam - $11.9 \%$; secondary school with the school-leaving exam 52.8\%; university graduates - 35.3\%. Czech Republic (CR): male entrepreneurs $(\mathrm{M})-71.1 \%$; female entrepreneurs $(\mathrm{F})-28.9 \%$; the age - up to 30 years $-16.7 \%$; from 31 to 50 years $-26.2 \%$; over 50 years - 57.1\%; the achieved education - secondary school without the school-leaving exam - 18.9\%; secondary school with the school-leaving exam $-47.8 \%$; university graduates $-33.3 \%$.

\section{RESULTS}

\subsection{Partial results of market risk}

The following Tables 1, 2, 3 and 4 summarise the results of the assessment of the market risk' sources (R11, R12, R13, R14) of entrepreneurs according to gender and the size of the enterprise. Also, there is comparison (Z-score) according to nationality of entrepreneurs. 
The structure of the entrepreneurs' answers (source R11 of market risk) according gender (G; F female, $\mathrm{M}$ - Male) and size of enterprise (SE; MSE - micro and small enterprise; ME - medium enterprise) were: SR: G(M/F) - V1 - 39/15; V2 - 61/29; V3 - 95/32; V4 - 75/45; V5 - 55/41 and SE(MSE/ME) - V1 - 51/3; V2 - 78/12; V3 - 109/18; V4 - 106/14; V5 - 85/11; CR: G(M/F) - V1 21/5; V2 - 58/28; V3 - 82/28; V4 - 78/24; V5 - 51/33 and SE(MSE/ME) - V1 - 25/1; V2 - 76/10; V3 - 97/13; V4 - 84/18; V5 - 75/9.

Table 1 The evaluation „involve loosing the customers“ by entrepreneurs

\begin{tabular}{|c|c|c|c|c|c|c|c|c|}
\hline \multirow{3}{*}{ R11 } & \multicolumn{4}{|c|}{ Size of Enterprise (SE) } & \multicolumn{4}{|c|}{ Gender $(G)$} \\
\hline & \multicolumn{2}{|c|}{ MSE } & \multicolumn{2}{|c|}{$\mathrm{ME}$} & \multicolumn{2}{|c|}{$\mathrm{F}$} & \multicolumn{2}{|c|}{$\mathrm{M}$} \\
\hline & SR & CR & SR & $\mathrm{CR}$ & SR & CR & SR & $\mathrm{CR}$ \\
\hline $\mathrm{V} 4+\mathrm{V} 5$ & 191 & 159 & 25 & 27 & 86 & 57 & 130 & 129 \\
\hline$[\%]$ & 44.5 & 44.5 & 43.1 & 52.9 & 53.1 & 48.3 & 40.0 & 44.5 \\
\hline $\begin{array}{l}\text { Z- score } \\
\text { (P- value) }\end{array}$ & \multicolumn{2}{|c|}{$\begin{array}{c}-0.004 \\
1.000\end{array}$} & \multicolumn{2}{|c|}{$\begin{array}{c}-1.026 \\
0.303\end{array}$} & \multicolumn{2}{|c|}{$\begin{array}{l}0.790 \\
0.429\end{array}$} & \multicolumn{2}{|c|}{$\begin{array}{r}-0.348 \\
0.726\end{array}$} \\
\hline
\end{tabular}

(Source: own data collection)

There are no statistically significant differences of evaluating (V4+V5) the involve loosing the customers between entrepreneurs of the Slovak Republic and Czech Republic according gender and size of enterprise (see Table 1; P- values of Z-score are greater than 0.05 ).

The structure of the entrepreneurs' answers (source R12 of market risk) according gender (F; M) and size of enterprise (MSE; ME) were: SR: G(M/F) - V1 - 17/7; V2 - 52/16; V3 - 109/55; V4 - 107/56; V5 - 40/28 and SE(MSE/ME) - V1 - 21/3; V2 - 61/7; V3 - 143/21; V4 - 142/21; V5 - 62/6; CR: $\mathrm{G}(\mathrm{M} / \mathrm{F})$ - V1 - 24/4; V2 - 45/19; V3 - 127/41; V4 - 64/38; V5 - 30/18 and SE(MSE/ME) - V1 28/0; V2 - 58/6; V3 - 146/22; V4 - 84/18; V5 - 41/5.

Table 2 The evaluation „strong competition in the line of business“ by entrepreneurs

\begin{tabular}{|c|c|c|c|c|c|c|c|c|}
\hline \multirow{3}{*}{ R12 } & \multicolumn{4}{|c|}{ Size of Enterprise (SE) } & \multicolumn{4}{|c|}{ Gender $(\mathrm{G})$} \\
\hline & \multicolumn{2}{|c|}{ MSE } & \multicolumn{2}{|c|}{$\mathrm{ME}$} & \multicolumn{2}{|c|}{$\mathrm{F}$} & \multicolumn{2}{|c|}{$\bar{M}$} \\
\hline & SR & CR & SR & CR & SR & CR & SR & CR \\
\hline $\mathrm{V} 4+\mathrm{V} 5$ & 204 & 125 & 27 & 23 & 84 & 54 & 147 & 94 \\
\hline$[\%]$ & 47.6 & 35.0 & 46.6 & 45.1 & 51.9 & 45.8 & 45.2 & 32.4 \\
\hline $\begin{array}{l}\text { Z- score } \\
\text { (P- value) }\end{array}$ & \multicolumn{2}{|c|}{$\begin{array}{c}3.548 \\
<0.001\end{array}$} & \multicolumn{2}{|c|}{$\begin{array}{l}0.152 \\
0.881\end{array}$} & \multicolumn{2}{|c|}{$\begin{array}{l}1.006 \\
0.312\end{array}$} & \multicolumn{2}{|c|}{$\begin{array}{l}3.250 \\
0.001\end{array}$} \\
\hline
\end{tabular}

(Source: own data collection)

There are statistically significant differences of evaluating (see Table 2; V4+V5) the strong competition in the line of business between entrepreneurs (male entrepreneurs; micro and small enterprise) of the Slovak Republic and Czech Republic (M: P-value of Z-score is 0.001; MSE: P-value of Z-score is less than 0.001).

The structure of the entrepreneurs' answers (source R13 of market risk) according gender (F; M) and size of enterprise (MSE; ME) were: SR: G(M/F) - V1 - 49/19; V2 - 72/39; V3 - 145/74; V4 - 42/19; V5 - 17/11 and SE(MSE/ME) - V1 - 62/6; V2 - 99/12; V3 - 192/27; V4 - 51/10; V5 - 25/3; CR: G(M/F) - V1 - 46/20; V2 - 78/28; V3 - 115/50; V4 - 43/18; V5 - 8/2 and SE(MSE/ME) - V1 61/5; V2 - 91/15; V3 - 147/18; V4 - 48/13; V5 - 10/0. 
Table 3 The evaluation „stagnation of the market“ by entrepreneurs

\begin{tabular}{|c|c|c|c|c|c|c|c|c|}
\hline \multirow{3}{*}{ R13 } & \multicolumn{4}{|c|}{ Size of Enterprise (SE) } & \multicolumn{4}{|c|}{ Gender $(\mathrm{G})$} \\
\hline & \multicolumn{2}{|c|}{ MSE } & \multicolumn{2}{|c|}{$\mathrm{ME}$} & \multicolumn{2}{|c|}{$\mathrm{F}$} & \multicolumn{2}{|c|}{$\mathrm{M}$} \\
\hline & SR & CR & SR & $\overline{C R}$ & SR & $\overline{\mathrm{CR}}$ & SR & $\overline{\mathrm{CR}}$ \\
\hline V4+V5 & 76 & 58 & 13 & 13 & 30 & 20 & 59 & 51 \\
\hline$[\%]$ & 17.7 & 16.2 & 22.4 & 25.5 & 18.5 & 16.9 & 18.2 & 17.6 \\
\hline $\begin{array}{l}\text { Z- score } \\
\text { (P- value) }\end{array}$ & \multicolumn{2}{|c|}{$\begin{array}{l}0.545 \\
0.582\end{array}$} & \multicolumn{2}{|c|}{$\begin{array}{c}-1.487 \\
0.136\end{array}$} & \multicolumn{2}{|c|}{$\begin{array}{l}0.339 \\
0.728\end{array}$} & \multicolumn{2}{|c|}{$\begin{array}{l}0.183 \\
0.857\end{array}$} \\
\hline
\end{tabular}

(Source: own data collection)

There are no statistically significant differences of evaluating (V4+V5) the stagnation of the market between entrepreneurs of the Slovak Republic and Czech Republic according gender and size of enterprise (see Table 3; P-values of Z-score are greater than 0.05).

The structure of the entrepreneurs' answers (source R14 of market risk) according gender (F; M) and size of enterprise (MSE; ME) were: SR: G(M/F) - V1 - 86/42; V2 - 103/57; V3 - 75/32; V4 - 48/22; V5 - 13/9 and SE(MSE/ME) - V1 - 118/10; V2 - 140/20; V3 - 93/14; V4 - 61/9; V5 - 17/5; CR: G(M/F) - V1 - 78/37; V2 - 84/38; V3 - 70/32; V4 - 46/8; V5 - 12/3 and SE(MSE/ME) - V1 106/9; V2 - 105/17; V3 - 91/11; V4 - 40/14; V5 - 15/0.

Table 4 The evaluation „unreliability of the suppliers“ by entrepreneurs

\begin{tabular}{|c|c|c|c|c|c|c|c|c|}
\hline \multirow{3}{*}{ R14 } & \multicolumn{4}{|c|}{ Size of Enterprise (SE) } & \multicolumn{4}{|c|}{ Gender $(G)$} \\
\hline & \multicolumn{2}{|c|}{ MSE } & \multicolumn{2}{|c|}{$\mathrm{ME}$} & \multicolumn{2}{|c|}{$\mathrm{F}$} & \multicolumn{2}{|c|}{$\mathrm{M}$} \\
\hline & SR & CR & SR & CR & SR & $\mathrm{CR}$ & SR & CR \\
\hline $\begin{array}{c}\mathrm{V} 4+\mathrm{V} 5 \\
{[\%]}\end{array}$ & $\begin{array}{c}78 \\
18.2\end{array}$ & $\begin{array}{c}55 \\
15.4\end{array}$ & $\begin{array}{c}14 \\
24.1\end{array}$ & $\begin{array}{c}14 \\
27.5\end{array}$ & $\begin{array}{c}31 \\
19.1\end{array}$ & $\begin{array}{l}11 \\
9.3\end{array}$ & $\begin{array}{c}61 \\
18.8\end{array}$ & $\begin{array}{c}58 \\
20.0\end{array}$ \\
\hline $\begin{array}{l}\text { Z- score } \\
\text { (P- value) }\end{array}$ & \multicolumn{2}{|c|}{$\begin{array}{l}1.033 \\
0.303\end{array}$} & \multicolumn{2}{|c|}{$\begin{array}{c}-1.306 \\
0.281\end{array}$} & \multicolumn{2}{|c|}{$\begin{array}{l}2.271 \\
0.023\end{array}$} & \multicolumn{2}{|c|}{$\begin{array}{c}-0.386 \\
0.696\end{array}$} \\
\hline
\end{tabular}

(Source: own data collection)

There are statistically significant differences of evaluating (V4+V5) the unreliability of the suppliers between entrepreneurs (female entrepreneurs) of the Slovak Republic and Czech Republic (see Table 4; F: P-value of Z-score is 0.023$)$.

The hypothesis H1A and the hypothesis H2A were rejected. Generally, no exist statistically significant differences of evaluating sources of market risk between SR and CR entrepreneurs according gender and size of enterprise.

\subsection{Partial results of economic risk}

The following Tables 5, 6, 7 and 8 summarise the results of the assessment of the economic risk' sources (R21, R22, R23, R24) of entrepreneurs according to gender and the size of the enterprise. Also, there is comparison ( $\mathrm{Z}$-score) according to nationality of entrepreneurs.

The structure of the entrepreneurs' answers (source R21 of economic risk) according gender (F; M) and size of enterprise (MSE; ME) were: SR: G(M/F) - V1 - 21/11; V2 - 49/23; V3 - 100/51; V4 83/47; V5 - 72/30 and SE(MSE/ME) - V1 - 30/2; V2 - 57/2; V3 - 129/22; V4 - 116/14; V5 - 97/5. CR: G(M/F) - V1 - 17/9; V2 - 43/20; V3 - 117/47; V4 - 42/11; V5 - 71/31 and SE(MSE/ME) V1 - 23/3; V2 - 54/9; V3 - 136/28; V4 - 92/10; V5 - 52/1. 
Table 5 The evaluation „development of the tax and insurance burden“ by entrepreneurs

\begin{tabular}{|c|c|c|c|c|c|c|c|c|}
\hline \multirow{3}{*}{ R21 } & \multicolumn{4}{|c|}{ Size of Enterprise (SE) } & \multicolumn{4}{|c|}{ Gender $(\mathrm{G})$} \\
\hline & \multicolumn{2}{|c|}{ MSE } & \multicolumn{2}{|c|}{$\mathrm{ME}$} & \multicolumn{2}{|c|}{$\mathrm{F}$} & \multicolumn{2}{|c|}{$\mathrm{M}$} \\
\hline & SR & CR & SR & CR & SR & CR & SR & CR \\
\hline $\mathrm{V} 4+\mathrm{V} 5$ & 213 & 144 & 19 & 11 & 77 & 42 & 155 & 113 \\
\hline$[\%]$ & 49.7 & 40.3 & 32.9 & 23.6 & 47.5 & 35.6 & 47.7 & 39.0 \\
\hline $\begin{array}{l}\text { Z- score } \\
\text { (P- value) }\end{array}$ & \multicolumn{2}{|c|}{$\begin{array}{l}2.611 \\
0.009\end{array}$} & \multicolumn{2}{|c|}{$\begin{array}{l}1.305 \\
0.190\end{array}$} & \multicolumn{2}{|c|}{$\begin{array}{l}1.995 \\
0.045\end{array}$} & \multicolumn{2}{|c|}{$\begin{array}{l}2.179 \\
0.029\end{array}$} \\
\hline
\end{tabular}

(Source: own data collection)

There are statistically significant differences of evaluating (see Table 5; V4+V5) the development of the tax and insurance burden between entrepreneurs (female and male entrepreneurs; micro and small enterprise) of the Slovak Republic and Czech Republic (MSE: P-value of Z-score is 0.009; F: P-value of $\mathrm{Z}$-score is 0.045; F: M-value of Z-score is 0.029).

The structure of the entrepreneurs' answers (source R22 of economic risk) according gender (F; M) and size of enterprise (MSE; ME) were: SR: G(M/F) - V1 - 49/19; V2 - 105/37; V3 - 105/66; V4 42/26; V5 - 24/14 and SE(MSE/ME) - V1 - 59/9; V2 - 120/22; V3 - 155/16; V4 - 59/9; V5 - 36/2; CR: G(M/F) - V1 - 58/20; V2 - 122/43; V3 - 81/41; V4 - 25/9; V5 - 4/5 and SE(MSE/ME) - V1 65/13; V2 - 142/23; V3 - 110/12; V4 - 31/3; V5 - 9/0.

Table 6 The evaluation „weak availability of the financial resources“ by entrepreneurs

\begin{tabular}{|c|c|c|c|c|c|c|c|c|}
\hline \multirow{3}{*}{ R22 } & \multicolumn{4}{|c|}{ Size of Enterprise (SE) } & \multicolumn{4}{|c|}{ Gender $(\mathrm{G})$} \\
\hline & \multicolumn{2}{|c|}{ MSE } & \multicolumn{2}{|c|}{ ME } & \multicolumn{2}{|c|}{$\mathrm{F}$} & \multicolumn{2}{|c|}{$\mathrm{M}$} \\
\hline & SR & CR & SR & CR & SR & CR & SR & CR \\
\hline $\mathrm{V} 4+\mathrm{V} 5$ & 95 & 40 & 11 & 3 & 40 & 14 & 66 & 29 \\
\hline$[\%]$ & 22.1 & 11.2 & 19.0 & 5.9 & 24.7 & 11.9 & 20.3 & 10.0 \\
\hline $\begin{array}{l}\text { Z- score } \\
\text { (P- value) }\end{array}$ & \multicolumn{2}{|c|}{$\begin{array}{c}4.049 \\
<0.001\end{array}$} & \multicolumn{2}{|c|}{$\begin{array}{l}2.037 \\
0.041\end{array}$} & \multicolumn{2}{|c|}{$\begin{array}{l}2.686 \\
0.007\end{array}$} & \multicolumn{2}{|c|}{$\begin{array}{c}3.531 \\
<0.001\end{array}$} \\
\hline
\end{tabular}

(Source: own data collection)

There are statistically significant differences of evaluating (V4+V5) the weak availability of the financial resources between entrepreneurs of the Slovak Republic and Czech Republic according gender and size of enterprise (see Table 6; P-values of Z-score are less than 0.05).

The structure of the entrepreneurs' answers (source R23 of economic risk) according gender (F; M) and size of enterprise (MSE; ME) were: SR: G(M/F) - V1 - 57/25; V2 - 116/43; V3 - 89/62; V4 52/23; V5 - 11/9 and SE(MSE/ME) - V1 - 76/6; V2 - 135/24; V3 - 129/22; V4 - 70/5; V5 - 19/1; CR: G(M/F) - V1 - 64/23; V2 - 119/52; V3 - 81/30; V4 - 23/10; V5 - 3/3 and SE(MSE/ME) - V1 - 76/11; V2 - 146/21; V3 - 97/14; V4 - 32/5; V5 - 6/0.

Table 7 The evaluation „development of the interest rates“ by entrepreneurs

\begin{tabular}{|c|c|c|c|c|c|c|c|c|}
\hline \multirow{2}{*}{ R23 } & \multicolumn{4}{|c|}{ Size of Enterprise (SE) } & \multicolumn{4}{c|}{ Gender (G) } \\
\cline { 2 - 9 } & \multicolumn{3}{|c|}{ MSE } & \multicolumn{2}{|c|}{ ME } & \multicolumn{3}{|c|}{ F } \\
\cline { 2 - 9 } & SR & CR & SR & CR & SR & CR & SR & CR \\
\hline V4+V5 & 89 & 38 & 6 & 5 & 32 & 13 & 63 & 26 \\
\hline
\end{tabular}




\begin{tabular}{|c|c|c|c|c|c|c|c|c|}
\hline$[\%]$ & 20.7 & 10.6 & 10.3 & 9.8 & 19.8 & 11.0 & 19.4 & 9.0 \\
\hline $\begin{array}{l}\text { Z- score } \\
\text { (P- value) }\end{array}$ & \multicolumn{2}{|c|}{$\begin{array}{c}3.831 \\
<0.001\end{array}$} & \multicolumn{2}{|c|}{$\begin{array}{l}0.093 \\
0.928\end{array}$} & \multicolumn{2}{|c|}{$\begin{array}{l}1.965 \\
0.049\end{array}$} & \multicolumn{2}{|c|}{$\begin{array}{l}3.666 \\
<0.001\end{array}$} \\
\hline
\end{tabular}

(Source: own data collection)

There are statistically significant differences of evaluating (see Table 7; V4+V5) the development of the interest rates between entrepreneurs (female and male entrepreneurs; micro and small enterprise) of the Slovak Republic and Czech Republic (MSE: P-value of Z-score is less than 0.001; F: P-value of Z-score is 0.049; F: M-value of Z-score is less than 0.001).

The structure of the entrepreneurs' answers (source R24 of economic risk) according gender (F; M) and size of enterprise (MSE; ME) were: SR: G(M/F) - V1 - 25/15; V2 - 71/30; V3 - 109/54; V4 91/41; V5 - 29/22 and SE(MSE/ME) - V1 - 38/2; V2 - 91/10; V3 - 139/24; V4 - 115/17; V5 46/5; CR: G(M/F) - V1 - 30/12; V2 - 79/38; V3 - 101/40; V4 - 64/22; V5 - 16/6 and SE(MSE/ME) - V1 - 41/1; V2 - 100/17; V3 - 118/23; V4 - 76/10; V5 - 22/0.

Table 8 The evaluation ,growing prices of all types of energy" by entrepreneurs

\begin{tabular}{|c|c|c|c|c|c|c|c|c|}
\hline \multirow{3}{*}{ R24 } & \multicolumn{4}{|c|}{ Size of Enterprise (SE) } & \multicolumn{4}{|c|}{ Gender $(G)$} \\
\hline & \multicolumn{2}{|c|}{ MSE } & \multicolumn{2}{|c|}{$\mathrm{ME}$} & \multicolumn{2}{|c|}{$\mathrm{F}$} & \multicolumn{2}{|c|}{$\mathrm{M}$} \\
\hline & SR & CR & SR & CR & SR & CR & SR & CR \\
\hline $\mathrm{V} 4+\mathrm{V} 5$ & 161 & 79 & 22 & 10 & 63 & 28 & 120 & 80 \\
\hline$[\%]$ & 37.5 & 22.1 & 37.9 & 19.6 & 38.9 & 23.7 & 36.9 & 27.6 \\
\hline $\begin{array}{l}\text { Z- score } \\
\text { (P-value) }\end{array}$ & \multicolumn{2}{|c|}{$\begin{array}{l}4.668 \\
<0.001\end{array}$} & \multicolumn{2}{|c|}{$\begin{array}{l}2.096 \\
0.036\end{array}$} & \multicolumn{2}{|c|}{$\begin{array}{l}2.674 \\
0.008\end{array}$} & \multicolumn{2}{|c|}{$\begin{array}{l}2.467 \\
0.013\end{array}$} \\
\hline
\end{tabular}

(Source: own data collection)

There are statistically significant differences of evaluating (V4+V5) the growing prices of all types of energy between entrepreneurs of the Slovak Republic and Czech Republic according gender and size of enterprise (see Table 8; P-values of Z-score are less than 0.05).

The hypothesis H1B and the hypothesis H2B were accepted. Generally, there are statistically significant differences of evaluating sources of economic risk between SR and CR entrepreneurs according gender and size of enterprise.

\subsection{Partial results of financial risk}

The following Tables 9, 10, 11 and 12 summarise the results of the assessment of the financial risk' sources (R31, R32, R33, R34) of entrepreneurs according to gender and the size of the enterprise. Also, there is comparison (Z-score) according to nationality of entrepreneurs.

The structure of the entrepreneurs' answers (source R31 of financial risk) according gender (F; M) and size of enterprise (MSE; ME) were: SR: G(M/F) - V1 - 37/19; V2 - 80/35; V3 - 106/48; V4 - 71/37; V5 - 31/23 and SE(MSE/ME) - V1 - 45/11; V2 - 102/13; V3 - 142/12; V4 - 93/15; V5 - 47/7; CR: $\mathrm{G}(\mathrm{M} / \mathrm{F})$ - V1 - 27/13; V2 - 75/20; V3 - 96/34; V4 - 68/39; V5 - 24/12 and SE(MSE/ME) - V1 36/4; V2 - 81/14; V3 - 114/16; V4 - 94/13; V5 - 32/4.

\section{Table 9 The evaluation „,insufficient company profit“ by entrepreneurs}

$$
\begin{array}{l|l|l}
\text { R31 } & \text { Size of Enterprise (SE) } & \text { Gender }(\mathrm{G})
\end{array}
$$




\begin{tabular}{|c|c|c|c|c|c|c|c|c|}
\hline \multirow{2}{*}{} & \multicolumn{2}{|c|}{ MSE } & \multicolumn{2}{c|}{ ME } & \multicolumn{2}{c|}{ F } & \multicolumn{2}{c|}{ M } \\
\cline { 2 - 9 } & SR & CR & SR & CR & SR & CR & SR & CR \\
\hline V4+V5 & 140 & 126 & 22 & 17 & 60 & 51 & 102 & 92 \\
{$[\%]$} & 32.6 & 35.3 & 37.9 & 33.3 & 37.0 & 43.2 & 31.4 & 31.7 \\
\hline Z- score & \multicolumn{2}{|c|}{-0.785} & \multicolumn{2}{|c|}{0.499} & \multicolumn{2}{|c|}{-1.044} & \multicolumn{2}{c|}{-0.090} \\
(P- value) & \multicolumn{2}{|c|}{0.435} & \multicolumn{2}{|c|}{0.617} & \multicolumn{2}{c|}{0.298} & \multicolumn{2}{c|}{0.928} \\
\hline
\end{tabular}

(Source: own data collection)

There are no statistically significant differences of evaluating (V4+V5) the insufficient company profit between entrepreneurs of the Slovak Republic and Czech Republic according gender and size of enterprise (see Table 9; P-values of Z-score are greater than 0.05).

The structure of the entrepreneurs' answers (source R32 of financial risk) according gender (F; M) and size of enterprise (MSE; ME) were: SR: G(M/F) - V1 - 107/53; V2 - 110/41; V3 - 58/40; V4 36/20; V5 - 14/8 and SE(MSE/ME) - V1 - 145/15; V2 - 140/11; V3 - 82/16; V4 - 45/11; V5 17/5; CR: G(M/F) - V1 - 117/452; V2 - 90/29; V3 - 44/26; V4 - 31/11; V5 - 8/7 and SE(MSE/ME) - V1 - 147/15; V2 - 103/16; V3 - 55/15; V4 - 37/5; V5 - 15/0.

Table 10 The evaluation ,indebtedness of the company“ by entrepreneurs

\begin{tabular}{|c|c|c|c|c|c|c|c|c|}
\hline \multirow{3}{*}{ R32 } & \multicolumn{4}{|c|}{ Size of Enterprise (SE) } & \multicolumn{4}{|c|}{ Gender $(G)$} \\
\hline & \multicolumn{2}{|c|}{ MSE } & \multicolumn{2}{|c|}{$\mathrm{ME}$} & \multicolumn{2}{|c|}{$\mathrm{F}$} & \multicolumn{2}{|c|}{$\mathrm{M}$} \\
\hline & $\begin{array}{l}\text { SR } \\
\end{array}$ & CR & SR & CR & $\overline{S R}$ & $\mathrm{CR}$ & SR & CR \\
\hline V4+V5 & 72 & 52 & 16 & 5 & 28 & 18 & 50 & 39 \\
\hline$[\%]$ & 16.8 & 14.6 & 27.6 & 9.8 & 17.3 & 15.3 & 15.4 & 13.4 \\
\hline Z- score & \multicolumn{2}{|c|}{$\begin{array}{l}0.849 \\
0.395\end{array}$} & \multicolumn{2}{|c|}{$\begin{array}{l}2.348 \\
0.019\end{array}$} & \multicolumn{2}{|c|}{$\begin{array}{l}0.453 \\
0.653\end{array}$} & \multicolumn{2}{|c|}{$\begin{array}{l}0.681 \\
0.497\end{array}$} \\
\hline
\end{tabular}

(Source: own data collection)

There are statistically significant differences of evaluating (V4+V5) the indebtedness of the company between entrepreneurs (medium enterprises) of the Slovak Republic and Czech Republic (see Table 10; ME: P-value of Z-score is 0.019).

The structure of the entrepreneurs' answers (source R33 of financial risk) according gender (F; M) and size of enterprise (MSE; ME) were: SR: G(M/F) - V1 - 104/45; V2 - 77/36; V3 - 64/39; V4 - 49/26; V5 - 31/16 and SE(MSE/ME) - V1 - 138/11; V2 - 104/9; V3 - 84/19; V4 - 65/10; V5 - 38/9; CR: $\mathrm{G}(\mathrm{M} / \mathrm{F})$ - V1 - 82/35; V2 - 66/31; V3 - 69/20; V4 - 58/25; V5 - 15/7 and SE(MSE/ME) - V1 105/12; V2 - 83/14; V3 - 74/15; V4 - 74/9; V5 - 21/1.

Table 11 The evaluation „unpaid receivables“ by entrepreneurs

\begin{tabular}{|c|c|c|c|c|c|c|c|c|}
\hline \multirow{3}{*}{ R33 } & \multicolumn{4}{|c|}{ Size of Enterprise (SE) } & \multicolumn{4}{|c|}{ Gender $(G)$} \\
\hline & \multicolumn{2}{|c|}{ MSE } & \multicolumn{2}{|c|}{$\mathrm{ME}$} & \multicolumn{2}{|c|}{$\mathrm{F}$} & \multicolumn{2}{|c|}{$\mathrm{M}$} \\
\hline & SR & CR & SR & CR & SR & CR & SR & CR \\
\hline V4+V5 & 103 & 95 & 19 & 10 & 42 & 32 & 80 & 73 \\
\hline$[\%]$ & 24.0 & 26.6 & 32.8 & 19.6 & 25.9 & 27.1 & 24.6 & 25.2 \\
\hline $\begin{array}{l}\text { Z- score } \\
\text { (P- value) }\end{array}$ & \multicolumn{2}{|c|}{$\begin{array}{c}-0.836 \\
0.401\end{array}$} & \multicolumn{2}{|c|}{$\begin{array}{l}1.550 \\
0.121\end{array}$} & \multicolumn{2}{|c|}{$\begin{array}{c}-0.223 \\
0.826\end{array}$} & \multicolumn{2}{|c|}{$\begin{array}{r}-0.159 \\
0.872\end{array}$} \\
\hline
\end{tabular}

(Source: own data collection) 
There are no statistically significant differences of evaluating (V4+V5) the unpaid receivables between entrepreneurs of the Slovak Republic and Czech Republic according gender and size of enterprise (see Table 11; P-values of Z-score are greater than 0.05).

The structure of the entrepreneurs' answers (source R34 of financial risk) according gender (F; M) and size of enterprise (MSE; ME) were: SR: G(M/F) - V1 - 121/58; V2 - 82/40; V3 - 65/32; V4 - 31/16; V5 - 26/16 and SE(MSE/ME) - V1 - 162/17; V2 - 108/14; V3 - 84/13; V4 - 39/8; V5 - 36/6; CR: G(M/F) - V1 - 96/39; V2 - 82/31; V3 - 56/21; V4 - 39/19; V5 - 17/8 and SE(MSE/ME) - V1 118/17; V2 - 101/12; V3 - 69/8; V4 - 48/10; V5 - 21/4.

Table 12 The evaluation ,inability to pay obligations (insolvency)“ by entrepreneurs

\begin{tabular}{|c|c|c|c|c|c|c|c|c|}
\hline \multirow{3}{*}{ R34 } & \multicolumn{4}{|c|}{ Size of Enterprise (SE) } & \multicolumn{4}{|c|}{ Gender $(\mathrm{G})$} \\
\hline & \multicolumn{2}{|c|}{ MSE } & \multicolumn{2}{|c|}{ ME } & \multicolumn{2}{|c|}{$\mathrm{F}$} & \multicolumn{2}{|c|}{$\mathrm{M}$} \\
\hline & SR & CR & SR & CR & SR & CR & $\begin{array}{l}\text { SR } \\
\end{array}$ & CR \\
\hline V4+V5 & 75 & 69 & 14 & 14 & 32 & 27 & 57 & 56 \\
\hline$[\%]$ & 17.5 & 19.3 & 24.1 & 27.5 & 19.8 & 22.9 & 17.5 & 19.3 \\
\hline $\begin{array}{l}\text { Z- score } \\
\text { (P- value) }\end{array}$ & \multicolumn{2}{|c|}{$\begin{array}{c}-0.666 \\
0.503\end{array}$} & \multicolumn{2}{|c|}{$\begin{array}{c}-0.395 \\
0.689\end{array}$} & \multicolumn{2}{|c|}{$\begin{array}{c}-0.634 \\
0.529\end{array}$} & \multicolumn{2}{|c|}{$\begin{array}{c}-0.566 \\
0.568\end{array}$} \\
\hline
\end{tabular}

(Source: own data collection)

There are no statistically significant differences of evaluating (V4+V5) the inability to pay obligations (insolvency) between entrepreneurs of the Slovak Republic and Czech Republic according gender and size of enterprise (see Table 12; P-value of Z-score are greater than 0.05).

The hypothesis $\mathrm{H} 1 \mathrm{C}$ and the hypothesis $\mathrm{H} 2 \mathrm{C}$ were rejected. Generally, no exist statistically significant differences of evaluating sources of financial risk between SR and CR entrepreneurs according gender and size of enterprise.

\section{DISCUSSION}

According to the entrepreneurs' evaluations, the most serious sources of market risk is losing customers. $44.9 \%$ of entrepreneurs (i.e. $402 / 895$ entrepreneurs) reported that losing costumers is a high or very high intensity market risk. There are no significant differences between SR and CR entrepreneurs according gender of entrepreneur and size of enterprise.

The management weaknesses are widely considered to be the most important internal growth constraint facing SMEs (Hudakova \& Dvorsky, 2019; Barbero et al., 2011). An important factor is whether the management of SMEs have the skills to be able to spot and to take opportunities when resources are scarce and information is expensive (Belas \& Sopkova, 2016).

According to the entrepreneurs' evaluations, the most serious sources of economic risk is development of the tax and insurance burden. $43.2 \%$ of entrepreneurs (i.e. 387/895 entrepreneurs) reported that development of the tax and insurance burden is a high or very high intensity economic risk. The gender of entrepreneur and size of enterprises between Slovak and Czech entrepreneurs is a significant factor of evaluating the sources of economic risk, as is development of the tax and insurance burden; weak availability of the financial resources (loans, foundations); development of the interest rates; growing prices of all types of energy. 
According to the entrepreneurs' evaluations, the most serious sources of financial risk is insufficient company profit. $34.1 \%$ of entrepreneurs (i.e. 305/895 entrepreneurs) reported that losing costumers is a high or very high intensity market risk. There are no significant differences between SR and CR entrepreneurs according gender of entrepreneur and size of enterprise.

\section{CONCLUSIONS}

The author compared the assessment of the source of market risk, economic and financial risk. The main criteria for comparison were the entrepreneur's gender and the size of the enterprise.

The article showed interesting results. Gender of entrepreneur and the size of the enterprise is important to the evaluation of sources of economic risk. Slovak entrepreneurs perceive sources of financial risk more intensively than Czech entrepreneurs.

The involvement of the risk management to the everyday activities of the managers will help the companies to prevent the entrepreneurial errors and to ensure correct management which is closely connected with the stated level of the risk acceptability.

This research provides valuable results regarding the business environment and risk management in small and medium-sized enterprises in the Czech and Slovak Republic.

However, the limitations of this study cannot be overlooked. These include the possibility that the entrepreneurs did not adequately understand the issues involved or that some statements in the questionnaire was expressed wrongly.

It is worth to concentrate our future research on the comparison of the other risks and their sources influencing the quality of the business environment (security risk, legislative risk, operational risk or corruption) according to the socio-economic characteristics of entrepreneurs.

\section{REFERENCES}

Barbero, J. L., Casillas, J. C., \& Feldman, H. D. (2011). Managerial capabilities and paths to growth as determinants of high-growth small and medium-sized enterprises. International Small Business Journal, 29(6), 671-694. https://doi.org/10.1177/0266242610378287

Belas, J., \& Sopkova, G. (2016). Significant determinants of the competitive environment for SMEs in the context of financial and credit risks. Journal of International Studies, 9(2), 139-149. https://doi.org/10.14254/2071-8330.2016/9-2/10

Bilan, Y., Mishchuk, H., \& Pylypchuk, R. (2017). Towards sustainable economic development via social entrepreneurship. Journal of Security and Sustainability Issues, 6(4), 691-702. https://doi.org/10.9770/issi.2017.6.4(13)

Buganová, K., \& Moricová, V. (2017). Innovation of education in risk and crisis management. Turkish Online Journal of Educational Technology, 2017(November Special Issue INTE), 177-182.

Degryse, H., Van Cayseele, P. (2000), "Relationship lending within a Bank-based system: Evidence from European small business data", Center of Economic Studies, Discusion Paper Series DPS 98.16, Available at: https://feb.kuleuven.be/eng/ew/discussionpapers/DPS98/DPS9816.pdf

Dobeš, K., Virglerová, Z., \& Kramoliš, J. (2019). Impact of selected factors on the perception of the macroeconomic and financial environment of smes (empirical study from czech republic and slovak republic). Scientific Papers of the University of Pardubice, Series D: Faculty of Economics and Administration, 45(1), 29-40.

Fabuš, M. (2017). Current development of business environment in slovakia and czech republic. Entrepreneurship and Issues, 5(1), 127-137. https://doi.org/10.9770/jesi.2017.5.1(10) 
Havierniková, K., \& Kordoš, M. (2019). Selected risks perceived by SMEs related to sustainable entrepreneurship in case of engagement into cluster cooperation. Entrepreneurship and Sustainability Issues, 6(4), 1680-1693. https://doi.org/10.9770/jesi.2019.6.4(9)

Hernandez Tinoco, M., \& Wilson, N. (2013). Financial distress and bankruptcy prediction among listed companies using accounting, market and macroeconomic variables. International Review of Financial Analysis, 30, 394-419. https://doi.org/10.1016/i.irfa.2013.02.013

Hudakova, M. \& Dvorsky, J. (2019). Analysis of the market risk sources in the small and medium-sized enterprises of transport. Communications - Scientific Letters of the University of Zilina, 21(4), 97-103.

Hudakova, M., \& Dvorsky, J. (2018). Assessing the risk and their sources in dependence on the rate of implementing the risk management process in the SMEs. Equilibrium-quarterly Journal of economics and economic policy, 13(3), 543-567. https://dx.doi.org/10.24136/eq.2018.027

Hudakova, M., Schönfeld, J., Dvorský, J., \& Lusková, M. (2017). The market risk analysis and methodology of its more effective management in SMEs in the Slovak republic. Montenegrin Journal of Economics, 13(2), 151-161. https://doi.org/10.14254/1800-5845/2017.13-2.10

Jegadeeshwaran, M., \& Basuvaraj, M. (2019). Impact of economic and banks specific determinants of credit risk of select indian private sector banks in the post financial crisis period. International Journal of Scientific and Technology Research, 8(9), 1162-1166.

Karpak, B., \& Topcu, I. (2010) Small medium manufacturing enterprices in Turkey: an analytic network process framework for prioritizing factors affecting success. International Journal of Production Economics, 125(1), 60-70. https://doi.org/10.1016/j.ijpe.2010.01.001

Ključnikov, A., Kozubíková, L., \& Sopková, G. (2017). The Payment Discipline of Small and Mediumsized Enterprises. Journal of Competitiveness, Vol. 9, Issue 2, pp. 45 - 61. https://doi.org/10.7441/joc.2017.02.04

Koisova, E., Habanik, J., Virglerova, Z., \& Rozsa, Z. (2017). Smes financing as an important factor of business environment in slovak republic regions. Montenegrin Journal of Economics, 13(2), 129-140. https://doi.org/10.14254/1800-5845/2017.13-2.8

Kozak, L. S., \& Danchuk, M. V. (2016). Evolution of enterprise risk management under current conditions of economic development: From fragmented to integrated. Actual Problems of Economics, 178(4), 23-29.

Lam, J. (2003), Enterprise risk management: from incentives to controls, John Wiley \& Sons, New Joersy, Canada.

Leon, F. (2015). Does bank competition alleviate credit constraints in developing countries? Journal of Banking and Finance, 57, 130-142. http://doi.org/10.1016/j.jbankfin.2015.04.005

Meyer, D. F., \& Meyer, N. (2017). Management of small and medium enterprise (SME) development: An analysis of stumbling blocks in a developing region. Polish Journal of Management Studies, 16(1), 127-141. https://doi.org/10.17512/pjms.2017.16.1.11

Mikušova, M. (2017). To be or not to be a business responsible for sustainable development? Survey from small Czech businesses. Econ. Res. Ekon. Istraživanja 2017, 30, 1318-1338. https://doi.org/10.1080/1331677X.2017.1355257

Oláh, J., Kovács, S., Virglerova, Z., Lakner, Z., Kovacova, M., \& Popp, J. (2019). Analysis and comparison of economic and financial risk sources in SMEs of the visegrad group and serbia. Sustainability (Switzerland), 11(7) https://doi.org/10.3390/su11071853

Petrenko, E., Iskakov, N., Metsyk, O., \& Khassanova, T. (2017). Ecosystem of entrepreneurship: Risks related to loss of trust in stability of economic environment in kazakhstan. Entrepreneurship and Sustainability Issues, 5(1), 105-115. https://doi.org/10.9770/jesi.2017.5.1(8)

Pochitaev, A., \& Filippova, I. (2016). Analysis of financial risks as an important stage in the formation of financial strategy of the company. Journal of Economics and Economic Education Research, 17(SpecialIssue2), 1-8.

Virglerová, Z. (2018). Differences in the Concept of Risk Management in V4 Countries. International Journal of Entrepreneurial Knowledge, 6(2), 100-109. https://doi.org/10.2478/IJEK-2018-0017 